\title{
Encuentros/AIRTH 2017 Conference
}

\author{
Florian Zach \\ Washington State University, USA \\ florian.zach@wsu.edu \\ Dejan Križaj \\ University of Primorska, Faculty of Tourism Studies - Turistica, Slovenia \\ dejan.krizaj@fts.upr.si \\ https://doi.org/10.26493/2335-4194.10.189
}

Innovation is a cornerstone of economic development, but interest in tourism and hospitality innovation comes and goes. Nevertheless, in recent years there has been a constant, yet small, stream of research in this area. The Alliance for Innovators and Researchers in Tourism and Hospitality (AIRTH) is a network of innovation minded scholars. The goal of AIRTH is to work with interested institutions to arrange for conferences, events and projects to put a permanent spotlight on innovation in tourism $\&$ hospitality management. These activities should be opportunities for scholars and practitioners alike to learn from each other and to initiate collaborative work.

The first AIRTH official event happened in Slovenia in March 2017 as the 6th International Tourism Conference Encuentros co-hosted by AIRTH and called a special tourism innovation 'road-trip conference' with its official title 'Innovation in Tourism and Hospitality - Preparing for the Future.'

The conference was organized by the Faculty of Tourism Studies, University of Primorska (Turistica) and Alliance for Innovators and Researchers in Tourism and Hospitality (AIRTH) at Encuentros Conference Center, Portorož, Slovenia. The conference focused on critical issues related to innovation in tourism and hospitality. It primarily served two purposes:

1. To understand innovation in tourism and hospitality with respect to (a) conditions that support and enable innovation, (b) meanings, scope and impacts of innovation, and (c) success factors in the practice of innovation.

2. To kick-start the AIRTH network in order to attract individuals by becoming (a) the home for researchers and scholars for intellectual exchanges, and (b) the go-to place for practitioners for ideas, experiences, and new tools.

Atfer the first presentation day, the participants, divided in groups and embarked on a day long trip to Slovenian tourism and hospitality businesses that mastered innovation and are recipients of the National Slovenian Tourism Innovation Award. This was followed by a third day's discussion and consensus session. A special part of the event was round table 'Innovative Tourism 2016, 2017 and Beyond' with 2016 National Slovenian Tourism Innovation Award winners.

Conference's program and proceedings are available at www.airth.global and and www.encuentros.si. In this journal's AIRTH/Encuentros section two full contributions are presented out of the full list of conference presentations:

Nakamura, K., Sakamoto, H., \& Križaj, D., Social value creation in art related tourism projects: The role of creative project actors in diverse national and international settings.

Brehm, L., Križaj, D., \& Pohjola, P., Generalizing of the EDIT model for non-tourism domains.

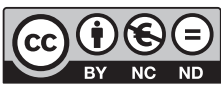

This paper is published under the terms of the Attribution- NonCommercial-NoDerivatives 4.0 International (CC B Y-NC-ND 4.0) License. 